\title{
Physician involvement enhances coding accuracy to ensure national standards: an initiative to improve awareness among new junior trainees
}

\author{
${ }^{1} \mathrm{~S}$ Nallasivan, ${ }^{2} \mathrm{~T}$ Gillott, ${ }^{3} \mathrm{~S}$ Kamath, ${ }^{4} \mathrm{~L}$ Blow, ${ }^{5} \mathrm{~V}$ Goddard \\ ${ }^{1}$ ST5 Rheumatology and Medicine; ${ }^{2}$ Consultant Rheumatologist; ${ }^{3}$ Consultant Physician, Department of Elderly Medicine; ${ }^{4}$ Clinical Coding \\ Services Manager; ${ }^{5}$ Clinical Coding Auditor, Diana Princess of Wales Hospital, Grimbsy, UK
}

\begin{abstract}
Record Keeping Standards is a development led by the Royal College of Physicians of London (RCP) Health Informatics Unit and funded by the National Health Service (NHS) Connecting for Health. A supplementary report produced by the RCP makes a number of recommendations based on a study held at an acute hospital trust. We audited the medical notes and coding to assess the accuracy, documentation by the junior doctors and also to correlate our findings with the RCP audit. Northern Lincolnshire \& Goole Hospitals NHS Foundation Trust has I I 4,000 'finished consultant episodes' per year. A total of 100 consecutive medical (50) and rheumatology (50) discharges from Diana Princess of Wales Hospital from August-October 2009 were reviewed. The results showed an improvement in coding accuracy ( $10 \%$ errors), comparable to the RCP audit but with $5 \%$ documentation errors. Physician involvement needs enhancing to improve the effectiveness and to ensure clinical safety.
\end{abstract}

KEYWORDS Coding, payment by results, rheumatology, Royal College of Physicians of London, physician involvement, audit commission

DECLARATION OF INTERESTS No conflict of interests declared.
Correspondence to S Nallasivan, Department of Rheumatology, Cravern Building, Hull Royal Infirmary, I4 Hartley Bridge, Victoria Docks Hull HU9 IQG, UK

tel. $+44(0) 1482620218$

e-mail nsmanil00@doctors.org.uk

\section{INTRODUCTION}

Professional Record Keeping Standards is a development led by the Royal College of Physician of London (RCP) Health Informatics Unit and funded by the National Health Service (NHS) Connecting for Health. The NHS requires the accurate input of data based on Office of Population, Censuses and Surveys classification, fourth revision (OPCS-4) and the International Statistical Classification of Diseases and Related Health Problems, tenth revision (ICD- I0) to reflect clinical activity. Trusts have a financial incentive to ensure that coding is accurate, comprehensive and timely. Since 1990 OPCS-4 (with revisions) has been implemented across the NHS.

As Professor lain Carpenter, Associate Director, Records Standards at the RCP, reported:

Implementing the Academy of Medical Royal Colleges' Record Keeping Standards can improve medical records and the accurate retrieval of important clinical data. This report also shows that using the standards would make clinical coding more efficient and accurate, reducing financial errors in the reimbursement of hospital activity - particularly in $2009 / 10$ with the introduction of HRG4 [Healthcare Resource Groups 4], which is more sensitive to coding accuracy and data quality.

A supplementary report produced by the RCP makes a number of recommendations based on a study held at an
TABLE I Cost analysis due to documentation error

\begin{tabular}{|l|l|l|l|}
\hline Diagnosis & $\begin{array}{l}\text { Trust } \\
\text { cost }\end{array}$ & Correct diagnosis & $\begin{array}{l}\text { Audit } \\
\text { cost }\end{array}$ \\
\hline $\begin{array}{l}\text { Deep-vein } \\
\text { thrombosis and } \\
\text { pneumonia }\end{array}$ & $£ 1,98 \mathrm{I}$ & $\begin{array}{l}\text { Lung abscess and } \\
\text { deep-vein thrombosis }\end{array}$ & $£ 4,942$ \\
\hline $\begin{array}{l}\text { Hip pain, } \\
\text { gastrointestinal } \\
\text { bleed }\end{array}$ & $£ 2,086$ & $\begin{array}{l}\text { Large bowel disease } \\
\text { with complications }\end{array}$ & $£ 2,875$ \\
\hline $\begin{array}{l}\text { Unspecified } \\
\text { respiratory } \\
\text { tract infection }\end{array}$ & $£ 3,618$ & Bronchopneumonia & $£ 3,959$ \\
\hline
\end{tabular}

acute hospital trust. These include ensuring that clinical coding is done using full medical notes rather than just a discharge summary; taking a consistent approach to medical record documentation; avoiding the duplication of administrative or clinical data; establishing regular meetings between clinical coding and audit teams and clinicians;' and ensuring that all staff recognise the need to keep notes in good order.

According to the Audit Commission report in 2008, the factors affecting coding accuracy relate to the need for clinician involvement in improving medical record documentation and guidance on co-morbidities.

At the Diana Princess of Wales Hospital (DPOW) - a district general hospital with a catchment population of 
about 400,000 - we elected to review the coding and audit the medical notes (hospital inpatient data: 'finished consultation episodes') across medical wards covering different specialties, as well as the rheumatology department. It is often thought in coding circles that hospital medical records have limited information for coding purposes, as junior doctors don't understand the coding concept. Hence this audit was undertaken with a view to analysing the notes, and providing feedback to doctors to enhance their understanding and maintain accurate medical records.

\section{AIMS AND OBJECTIVES}

The aims of this audit were:

- To evaluate the quality of coded clinical data by making comparisons between the information held on the Patient Administration System (PAS) and the information recorded in the health records and discharge summaries, ensuring adherence to national standards.

- To provide recommendations to ensure that data quality is maintained and improved thereby ensuring patient safety.

- To promote more clinician involvement with an emphasis on documentation.

\section{METHODOLOGY}

The audit was based on the methodology detailed in the Connecting for Health (CFH) publication, Clinical Coding Instruction Manual (version 3.0). ${ }^{2}$ This document provides guidance on conducting a clinical coding audit.

We reviewed the medical notes of patients discharged from medical wards and rheumatology wards between August-October 2009. The timing included the new intake of trainees beginning August 2009. Data were collected from 100 case notes (a random selection of 50 from medicine and 50 from rheumatology) as the remaining 30 couldn't be tracked in time. Rheumatology was reviewed separately because of evidence of poor coding accuracy nationally. ${ }^{3}$

A standard audit worksheet was completed for each episode and comparisons were then made between the information extracted from the health records by the auditor and the information provided by the trust on the PAS extract. The coders used the Dialect encoder using Clinical Terms Version 3. Medical registrar input was sought along with data checks when clarifying details in the medical notes.

\section{RESULTS}

Because rheumatology was under a different medical business unit, the audit data for rheumatology and medicine were analysed separately, but the datasets and criteria were the same. Electronic discharge summaries were not analysed in this work to maximise coding accuracy.The four major categories were primary diagnosis, secondary diagnosis that includes previous medical problems, primary procedure and secondary procedure.

Out of the 100 episodes analysed there were 74 correct primary diagnoses; with three errors at three-character level. There were 432 secondary diagnoses of which 342 (79.16\%) were correct.A total of 69 primary procedures were recorded of which 62 (89.85\%) were correct; with two errors at three-character level. There were 42 secondary procedures recorded of which 30 (7I.43\%) were correct. When we reviewed the patient notes from medical wards, documentation error accounted for $3 \%$. For example, one patient had cellulitis but was coded as having deep-vein thrombosis. Another patient had emphysema, but was coded as lung atelectasis based on the radiological report. A further patient was admitted with hip pain and then subsequently had a gastrointestinal bleed, congestive cardiac failure and renal impairment and was coded as musculoskeletal disease with complications, whereas it should have been large bowel disease with complications (see Table I).

Coding error accounted for 10\%, which includes incorrectly sequenced, omitted, four-character level errors. Secondary diagnosis accuracy was $78 \%$. In $18 \%$ of audited cases there was no electronic discharge summary.

On reviewing rheumatology inpatient notes $(n=50)$ :

- Primary diagnosis was correct: $37 / 50(74 \%)$;

- Secondary diagnosis: $129 / 159$ (81\%);

- Documentation issue: 2 notes;

- Procedures: 4 I/44 (93\%);

- Secondary procedures incorrect: $10 / 18$ (55\%).

We calculated the cost of the hospital stay before and after the audit based on the tariff by 'payment by results' and the net difference was very small $(\epsilon|3|$ for DPOW, compared with $£ 206$ in the RCP audit; see Table 2).

TABLE 2 Total tariff by 'payment by results'

\begin{tabular}{|l|l|l|l|}
\hline & $\begin{array}{l}\text { Pre-audit cost } \\
\text { by coders* }^{*}\end{array}$ & $\begin{array}{l}\text { Cost after } \\
\text { auditing }^{\dagger}\end{array}$ & Net \\
\hline $\begin{array}{l}\text { Diana Princess of } \\
\text { Wales Hospital } \\
\text { (DPOW) }\end{array}$ & $£ 43,594$ & $£ 42,453$ & $£|4|$ \\
\hline $\begin{array}{l}\text { Royal College } \\
\text { of Physicians of } \\
\text { London (RCP) }\end{array}$ & $£ 78,846^{\pi}$ & $£ 79,640$ & $£ 206$ \\
\hline
\end{tabular}

"Cost was based on the coding by Patient Administration System including errors. 'Cost based on the audit after correcting any errors. "Difference in the cost between DPOW Hospital and $\mathrm{RCP}$ audit is due to the difference in number of episodes audited. 


\section{CONCLUSIONS}

On the whole, there was a good standard of coding and documentation, but avoidable errors still occurred - a concern since errors in discharge summaries could mislead general practitioners and put patient safety risk.

This audit is based on a small number of case notes and hence the negligible financial impact of inaccurate coding could not be extrapolated for the whole financial year. Electronic discharge summaries were not taken into consideration in this piece of work.

\section{RECOMMENDATIONS}

- To continue to encourage doctors to document appropriately and maintain the record keeping standards as envisaged in RCP guidelines. ${ }^{4}$

- As accurate documentation is vital to ensure patient safety and care, to arrange regular interactions between clinicians and coding staff, to reaudit regularly and ensure the recommendations are implemented.

- To create more awareness of clinical coding throughout the trust, highlighting the importance of high quality coded data. The Clinical Coding Service Manager and Clinical Coding Trainer are to attend monthly business unit meetings and the junior doctors' induction.

- Re-audit the similar set of data during the subsequent year to ensure deficiencies are corrected as suggested.

\section{DISCUSSION}

This audit suggests that interaction with physicians is beneficial to the clinical coding team, and can achieve appropriate coding of high quality data. This may influence the net income to the trust. Our analysis showed that $74 \%$ of coding had the correct diagnosis and $91 \%$ mentioned procedures correctly. Documentation error was found in $5 \%$. This is similar to the RCP audit results. Though the data is limited it gives a fair insight into the process of coding, documentation inaccuracies and the impact on the financial position. Our data are comparable to published national statistics.

As all general practitioners receive electronic discharge summaries $^{4}$ of hospital inpatients any errors in even secondary diagnoses could mislead and affect patient safety. In addition, more emphasis should be placed on proper completion of the summaries.

In the annual audit letter (2008/2009) from the audit commission, ${ }^{6}$ during the analysis of inpatients at Northern Lincolnshire \& Goole Hospitals Foundation Trust (reported in January 2009) it was found that the trust's coding accuracy had not improved compared to 2007/08. There is, therefore, some inaccuracy in the income due to the trust from commissioners. However, the error rate of $6.7 \%$ found in our sample is lower than the trust average of $9.4 \%$.

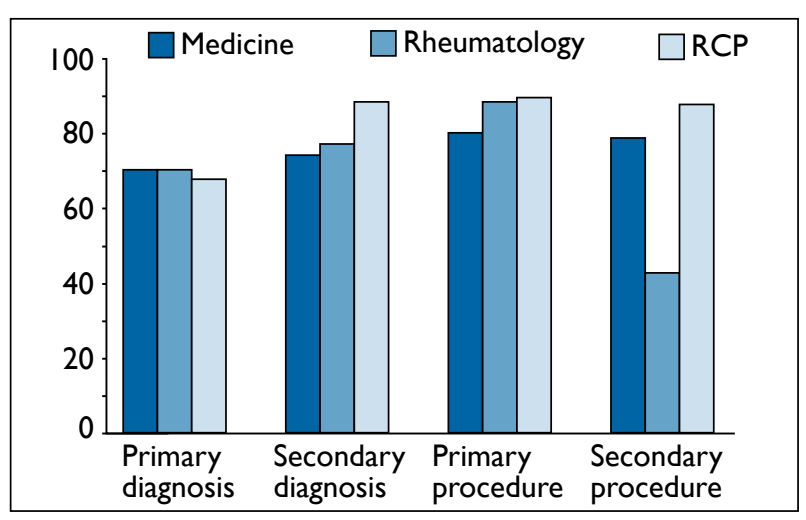

FIGURE I Comparison of coding accuracy in Diana Princess of Wales Hospital audit and Royal College of Physicians of London audit (medicine and rheumatology).

A number of recommendations have been agreed between the trust and Northeast Lincolnshire Care Trust Plus to improve accuracy of coding.

Following this audit, the results were discussed in the local audit meeting and efforts to create awareness have been made among clinicians and junior doctors with a view to making documentation more clear thereby ensuring that coding is appropriate. We included the concept of coding and medical records documentation in the core medical training day to highlight its importance and it was also stressed during the new Foundation and core medical trainees induction programme in August 2010.

It is hoped to expand this initiative and to continue to engage coders and doctors to make it efficient. Re-audit is planned to make sure recommendations are implemented and to complete the audit cycle.

\section{REFERENCES}

I Royal College of Physicians of London. Improving clinical records and clinical coding together. London: Audit Commission; 2009. Available from http://www.audit-commission.gov.uk/SiteCollection Documents/AuditCommissionReports/NationalStudies/20090827 pbrdataassuranceframework0809physiciansreport.pdf

2 National Health Service Connecting for Health. Clinical Coding Instruction Manual. Version 3.0. NHS CFH; 2009.

3 Audit Commission. PbR Data Assurance Framework 2007/08: findings from the first year of the coding audit programme. London: Audit Commission; 2008. Available from http://www.audit-commission. gov.uk/SiteCollectionDocuments/AuditCommissionReports/ NationalStudies/PbRreport.pdf

4 Royal College of Physicians of London Health Informatics Unit. A clinician's guide to record standards - part 2: standards for the structure and content of medical communications when patients are admitted to hospital. London: NHS Digital and Health information Policy Directorate; 2008. Available from http://www.rcoa.ac.uk/docs/ Clinicians-Guide-Part-2-Standards.pdf

5 Royal College of Physicians of London Health Informatics Unit.Top ten tips for coding - a guide for clinical staff. London: RCP; 2007. Available from http://www.ic.nhs.uk/webfiles/Clinical/Top_Ten_ Tips_for_Coding_A_Guide_for_Clinical_Staff.pdf

6 Audit Commission. North East Lincolnshire Care Trust Plus annual audit letter 2009/10. Available from http://www.audit-commission. gov.uk/health/audit/annualauditletters/pages/default.aspx 